\title{
Model Gamifikasi Menggunakan Logika Fuzzy untuk Penentuan Reward Pelanggan pada E-Commerce
}

Gamification Model using Fuzzy Logic for Customer Reward Determination on ECommerce

\author{
Ichwan Setiarso ${ }^{1}$, Moch. Sjamsul Hidajat ${ }^{2}$ \\ ${ }^{1,2}$ Manajemen Informatika, STMIK Kadiri Kediri, Jawa Timur, Indonesia \\ E-mail: 1ichwan10stmik@gmail.com, ${ }^{2}$ gus.sjamsul@gmail.com
}

\begin{abstract}
Abstrak
Inovasi menggunakan gamifikasi diperlukan untuk menghadapi persaingan antar e-commerce. Gamifikasi berguna untuk meningkatkan pengalaman, menjaga kesetiaan pelanggan, penguatan merk dan melengkapi motivasi pembeli dan melakukan transaksi di e-commerce. Bentuk yang umum dari gamifikasi adalah pemberian reward bagi pelanggan dengan kondisi tertentu. Kondisi ini contohnya adalah lama menjadi pelanggan, besar transaksi, jenis transaksi. Masalah yang terjadi berkaitan dengan pemberian reward kepada pelanggan adalah reward yang tidak sesuai dan monoton atau mudah ditebak sehingga unsur kejutan yang menjadi salah satu elemen penting dari reward menjadi menurun kualitasnya. Penelitian ini bertujuan membentuk model gamifikasi yang tidak monoton menggunakan kecerdasan buatan dengan metode logika fuzzy. Logika fuzzy mampu membentuk perilaku reward yang dinamis sehingga meningkatkan kualitas reward yang diberikan kepada pelanggan. Input yang digunakan untuk menentukan reward adalah banyaknya transaksi, banyak produk dipilih dan total biaya pesanan. Hasil dari penelitian ini, logika fuzzy dapat menghasilkan perilaku reward yang lebih dinamis.
\end{abstract}

Kata kunci: gamifikasi, reward, logika fuzzy, e-commerce

\begin{abstract}
Innovation using gamification is needed to face competition between e-commerce. Gamification is useful for enhancing the experience, maintaining customer loyalty, strengthening the brand and completing the buyer's motivation and conducting transactions in e-commerce. A common form of gamification is rewarding customers with certain conditions. This condition for example is a long time a customer, large transactions, types of transactions. Problems that occur related to giving rewards to customers are rewards that are not appropriate and monotonous or easily predictable so that the element of surprise which is one of the important elements of reward is decreasing in quality. This study aims to form a non-monotonous gamification model using artificial intelligence with the fuzzy logic method. Fuzzy logic is able to form dynamic reward behaviors that improve the quality of rewards given to customers. The input used to determine the reward is the number of transactions, many products selected and the total cost of the order. The results of this study, fuzzy logic can produce more dynamic reward behavior.
\end{abstract}

Keywords: gamification, reward, fuzzy logic, e-commerce

\section{PENDAHULUAN}

Data menunjukkan bahwa jumlah kemiskinan berbanding lurus dengan jumlah pengangguran. Hal ini ditunjukkan pada data tahun 2004 sampai 2014 yang menyebutkan bahwa penurunan pengangguran diikuti dengan penurunan kemiskinan juga [1]. Usaha Mikro, 
Kecil dan Menengah (UMKM) mempunyai peran besar dalam penurunan ini dalam menyediakan lapangan kerja di masyarakat. Data dari Badan Pusat Statistik [2] menunjukkan perkembangan UMKM yang mengalami kenaikan dari tahun ke tahun dan menyerap 97\% dari tenaga kerja nasional serta menyumbang 57,12 persen pada Pendapatan Domestik Bruto (PDB) negara, dimana 38,81 persen adalah berasal dari Usaha Mikro [3]. Kesimpulan dari data tersebut mengindikasikan peran besar dari UMKM terhadap penurunan jumlah kemiskinan dan pengangguran di Indonesia.

E-commerce telah menjadi media utama dari UMKM di Indonesia saat ini untuk memasarkan produknya. Dengan meningkatnya jumlah e-commerce maka dibutuhkan inovasi untuk memenangkan persaingan. Gamifikasi dapat diterapkan pada sistem transaksi online yang bertujuan untuk meningkatkan pengalaman, loyalty, brand awareness, dan motivasi dalam melakukan transaksi jual beli [4]. Gamifikasi adalah penerapan dan penggunaan elemen desain game ke dalam konteks non-game [5], dimana dalam penelitian ini konteks yang dimaksud adalah e-commerce. Gamifikasi telah digunakan secara luas di bidang bisnis [6], lebih dari $70 \%$ perusahaan yang disurvei oleh Forbes berencana akan menggunakan gamifikasi dalam strategi penjualan produknya. Beberapa hasil penerapan gamifikasi antara lain adalah Ford yang berhasil menjaring lebih dari 100.000 pengunjung baru dalam sehari di websitenya, Wendy's yang mengalami peningkatan pada penjualan onlinenya dan jumlah pengguna baru di website campusfood.com yang meningkat 15 sampai 20\% [7]. Namun di samping itu, tingkat kegagalan gamifikasi juga diprediksi sangat tinggi, mencapai $80 \%$, yang disebabkan karena konsep dan desain elemen game yang buruk, pola pemberian reward yang monoton dan mudah ditebak [8].

Reward adalah salah satu elemen vital dalam gamifikasi. Kecerdasan buatan dapat diterapkan dalam gamifikasi untuk menentukan reward yang akan diberikan kepada pelanggan supaya lebih dinamis dan tidak monoton. Penelitian yang dilakukan oleh [9] menerapkan algoritma berbasis profil untuk personalisasi gamifikasi dalam lingkungan pembelajaran yang didukung oleh komputer. Kemudian [10] membahas tentang potensi machine learning dalam personalisasi gamifikasi. Personalisasi ini dilakukan dengan cara mempelajari pola data konsumen dan memanfaatkannya sebagai input dalam proses gamifikasi. Berkaitan dengan model data input ini, penelitian yang dilakukan oleh [11] memberikan gambaran jenis data yang dapat digunakan sebagai input untuk personalisasi gamifikasi. Penelitian yang dilakukan oleh [12] menerapkan mekanisme adaptif pada lima fitur gamifikasi dalam pembelajaran. Pendekatan berbasis data juga dilakukan oleh [13] dalam menganalisa perilaku pengguna dalam personalisasi pada platform gamifikasi. Penelitian-penelitian tersebut menggunakan data kuantitatif untuk personalisasi gamifikasi, namun jarang yang menggunakan data intuitif. Dan juga tidak banyak yang membahas personalisasi pada bagian spesifik gamifikasi, seperti pemberian reward. Penelitian ini akan merancang model gamifikasi intuitif menggunakan logika fuzzy yang akan diterapkan untuk mengatur perilaku dinamis reward pada pelanggan dalam personalisasi gamifikasi untuk e-commerce. Logika fuzzy adalah metode dalam kecerdasan buatan yang bekerja dengan data dan output intuitif, dan banyak digunakan untuk menyusun elemen adaptif dan dinamis dalam game, seperti yang dilakukan oleh [14] untuk menentukan item adaptif, penentuan skor [15], dan juga untuk menentukan perilaku Non-Playable Character (NPC) pada game sejarah Geger Pacinan [16].

\section{METODE PENELITIAN}

Berdasarkan hasil dari analisis data maka dibutuhkan metode untuk membuat pemberian reward dengan dinamis. Tahapan yang didapat berdasarkan analisis yang ada maka dihasilkan sebagai berikut : 


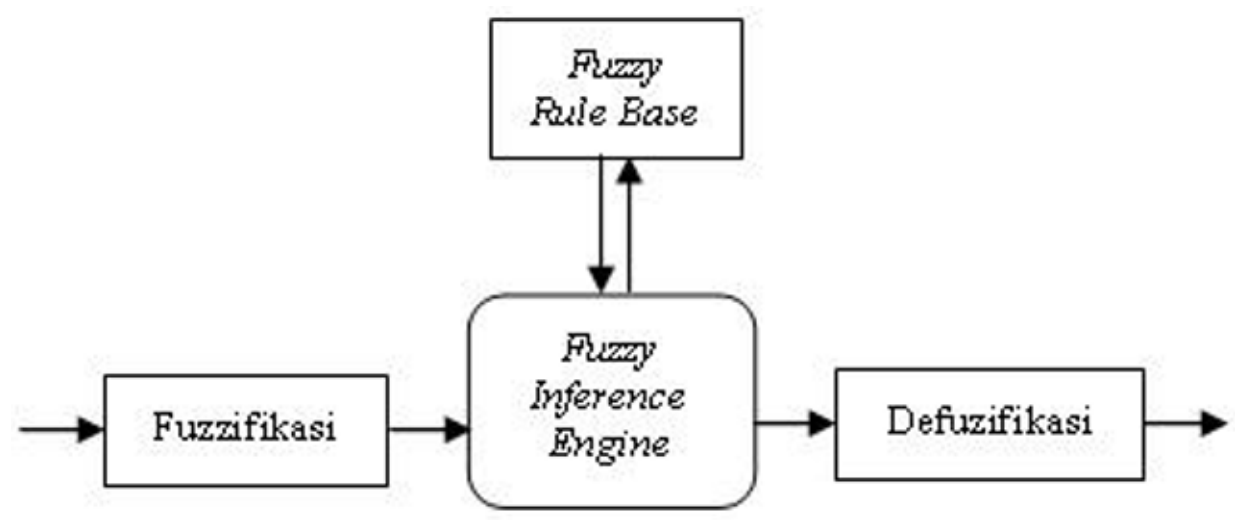

Gambar 1 Tahapan Fuzzy

Pemilihan parameter input adalah tahap pertama dalam perancangan penelitian ini. Untuk mendapatkan reward maka parameter yang akan dipilih adalah sebagai berikut :

1. Banyak Transaksi (BT) didapat dari total transaksi dalam kurun waktu 30 hari.

2. Banyak Produk dipilih (BP) didapat dalam satu pesanan atau orderan dan terdapat jumlah keseluruhan barang dari pembeli.

3. Total Biaya Pesanan (TB) didapat dari total biaya yang harus dibayarkan kepada pembeli untuk menyelesaikan pesanannya.

Dari parameter-parameter intput tersebut, maka akan berdampak pada reward yang akan didapat kepada pembeli. Reward sendiri adalah hadiah yang akan diberikan kepada pembeli setelah menyelesaikan semua tahapan. Pemberian berupa poin yang bisa ditukarkan dengan produk yang ada.

\subsection{Fuzzifikasi}

Fuzzifikasi dilakukan untuk mengkonversi data kuantitatif menjadi data intuitif menggunakan fungsi keanggotaan. Fungsi keanggotaan menentukan seberapa bobot intuitif dari masing-masing input. Sumbu x pada fungsi keanggotaan adalah data input yang akan dikonversi sedangkan sumbu y adalah bobot intuitif dari data input tersebut dengan kisaran nilai minimum 0 dan maksimum adalah 1. Bobot intuitif semakin besar jika semakin mendekati 1. Gambar 2 adalah fungsi keanggotaan untuk variabel Banyak Transaksi (BT). Gambar 3 menunjukkan fungsi keanggotaan untuk Banyak Produk (BP), dan Gambar 4 untuk Total Belanja (TB).

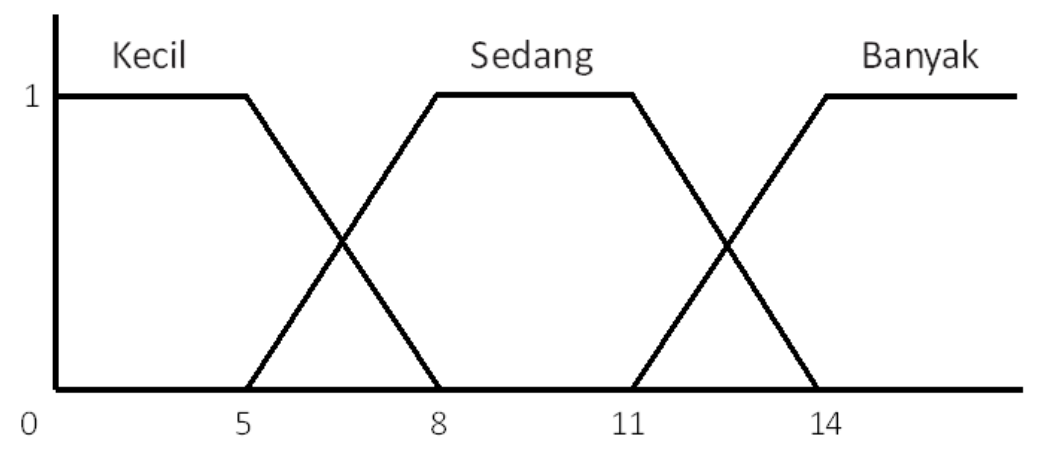


Techno.COM, Vol. 19, No. 1, Februari 2020: 87-96

$$
\begin{aligned}
& \text { HKecil }=\left\{\begin{array}{cc}
0 & x \geq 8 \\
\frac{8-x}{8-5} & 5<x<8 \\
1 & x \leq 5
\end{array}\right. \\
& \mu \text { Sedang }=\left\{\begin{array}{cc}
0 & X \leq 5 ; x \geq 14 \\
\frac{x-5}{8-5} & 5<x<8 \\
\frac{14-x}{14-11} & 11<x<14 \\
1 & 8 \leq x \leq 11
\end{array}\right.
\end{aligned}
$$

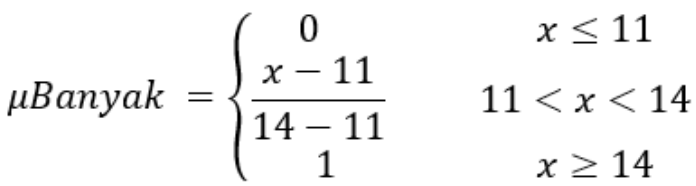

Gambar 2 Fungsi Keanggotaan untuk Banyak Transaksi (BT)

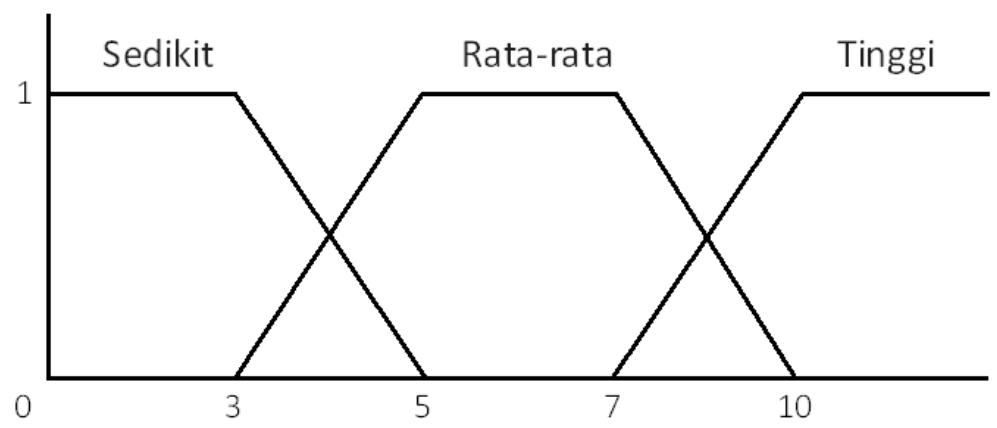

$$
\begin{aligned}
& \mu \text { Sedikit }=\left\{\begin{array}{cc}
0 & x \geq 5 \\
\frac{5-x}{5-3} & 3<x<5 \\
1 & x \leq 3
\end{array}\right. \\
& \mu \text { Rata }- \text { rata }=\left\{\begin{array}{cc}
0 & X \leq 3 ; x \geq 10 \\
\frac{x-3}{3-5} & 3<x<5 \\
\frac{10-x}{10-7} & 7<x<10 \\
1 & 5 \leq x \leq 7
\end{array}\right. \\
& \text { } \text { TTinggi }=\left\{\begin{array}{cc}
0 & x \leq 7 \\
\frac{x-7}{10-7} & 7<x<10 \\
1 & x \geq 10
\end{array}\right.
\end{aligned}
$$

Gambar 3 Fungsi Keanggotaan untuk Banyak Produk (BP) 


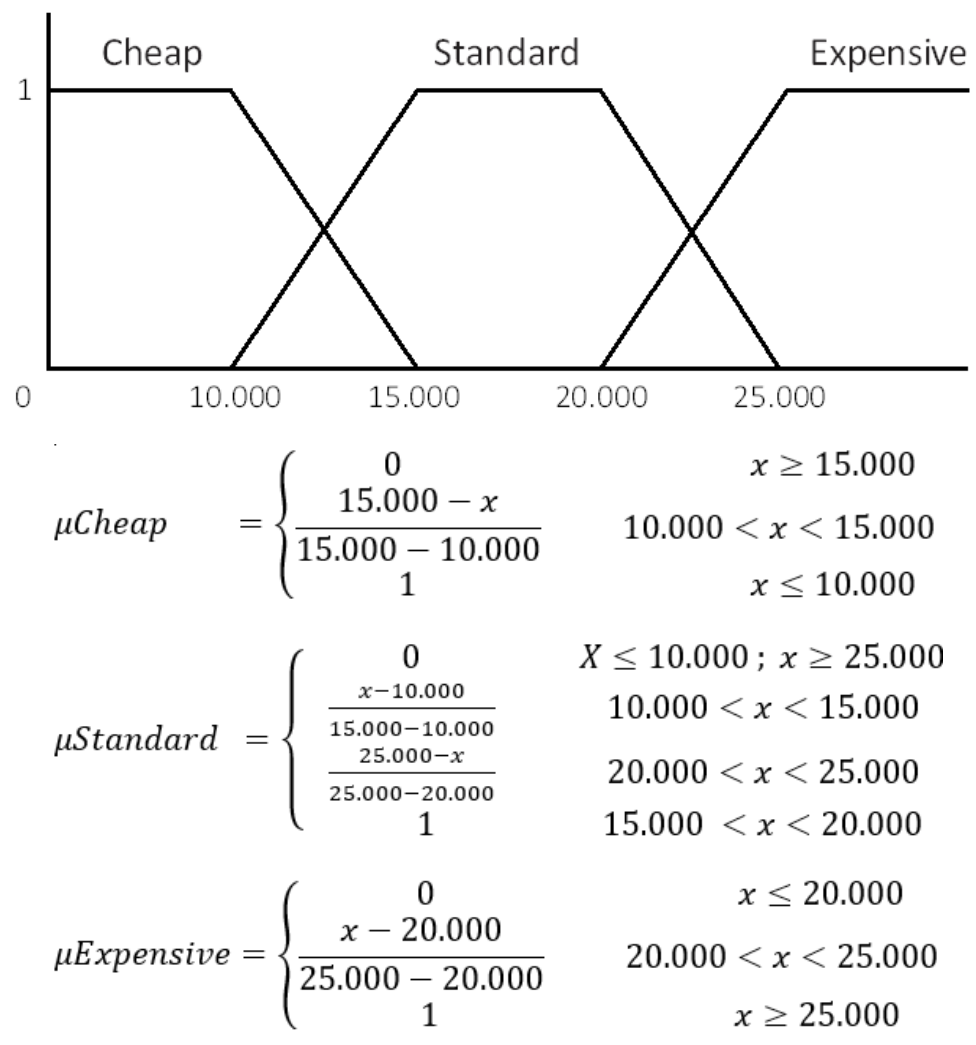

Gambar 4 Fungsi Keanggotaan untuk Total Belanja (TB)

Fungsi keanggotaan untuk data input di atas akan menghasilkan penentuan reward dengan fungsi keanggotaan ditunjukkan pada Gambar 5 berikut. Sumbu x adalah poin kuantitatif untuk reward dan sumbu y menunjukkan bobot intuitifnya.

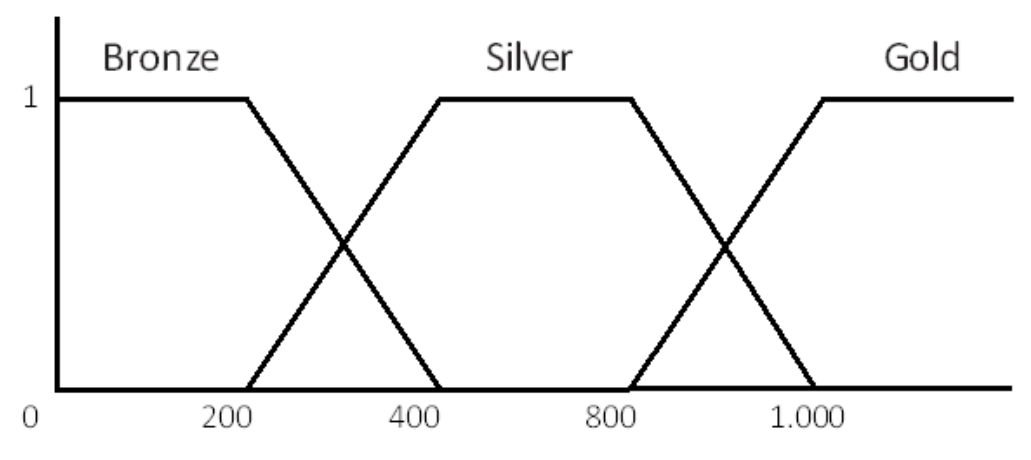

Gambar 5 Fungsi Keanggotaan untuk Reward

\subsection{Inferensi}

Bagian berikutnya dalam sistem fuzzy adalah aturan inferensi yang digunakan untuk menghasilkan output reward dari variabel input yang ada. Secara keseluruhan ada 27 aturan yang terbentuk ditunjukkan pada Tabel 1 berikut. 
Tabel 1 Daftar aturan inferensi

\begin{tabular}{|c|c|c|c|c|c|}
\hline No & Rule & BT & BP & TB & Reward \\
\hline 1 & 1 & Kecil & Sedikit & Cheap & Bronze \\
\hline 2 & 2 & Kecil & Sedikit & Standard & Bronze \\
\hline 3 & 3 & Kecil & Rata-rata & Cheap & Bronze \\
\hline 4 & 4 & Kecil & Rata-rata & Standard & Bronze \\
\hline 5 & 5 & Kecil & Tinggi & Cheap & Bronze \\
\hline 6 & 6 & Kecil & Tinggi & Standard & Bronze \\
\hline 7 & 7 & Sedang & Sedikit & Cheap & Bronze \\
\hline 8 & 8 & Sedang & Rata-rata & Cheap & Bronze \\
\hline 9 & 9 & Kecil & Sedikit & Expensive & Silver \\
\hline 10 & 10 & Kecil & Rata-rata & Expensive & Silver \\
\hline 11 & 11 & Kecil & Tinggi & Expensive & Silver \\
\hline 12 & 12 & Sedang & Sedikit & Standard & Silver \\
\hline 13 & 13 & Sedang & Sedikit & Expensive & Silver \\
\hline 14 & 14 & Sedang & Rata-rata & Standard & Silver \\
\hline 15 & 15 & Sedang & Tinggi & Cheap & Silver \\
\hline 16 & 16 & Sedang & Tinggi & Standard & Silver \\
\hline 17 & 17 & Banyak & Sedikit & Cheap & Silver \\
\hline 18 & 18 & Banyak & Sedikit & Standard & Silver \\
\hline 19 & 19 & Banyak & Rata-rata & Cheap & Silver \\
\hline 20 & 20 & Banyak & Tinggi & Cheap & Silver \\
\hline 21 & 21 & Sedang & Rata-rata & Expensive & Gold \\
\hline 22 & 22 & Sedang & Tinggi & Expensive & Gold \\
\hline 23 & 23 & Banyak & Sedikit & Expensive & Gold \\
\hline 24 & 24 & Banyak & Rata-rata & Standard & Gold \\
\hline 25 & 25 & Banyak & Rata-rata & Expensive & Gold \\
\hline 26 & 26 & Banyak & Tinggi & Standard & Gold \\
\hline 27 & 27 & Banyak & Tinggi & Expensive & Gold \\
\hline
\end{tabular}

\subsection{Defuzzifikasi}

Tahap ini digunakan untuk mengubah hasil perhitungan intuitif menjadi output kuantitatif, yang dilakukan dengan rumus (1) sebagai berikut.

$$
y=\frac{\sum y \mu_{R}(y)}{\sum \mu_{R}(y)}
$$

\subsection{Model umum sistem gamifikasi}

Model umum dari sistem gamifikasi untuk penentuan reward ditunjukkan pada Gambar 6 sebagai berikut. 


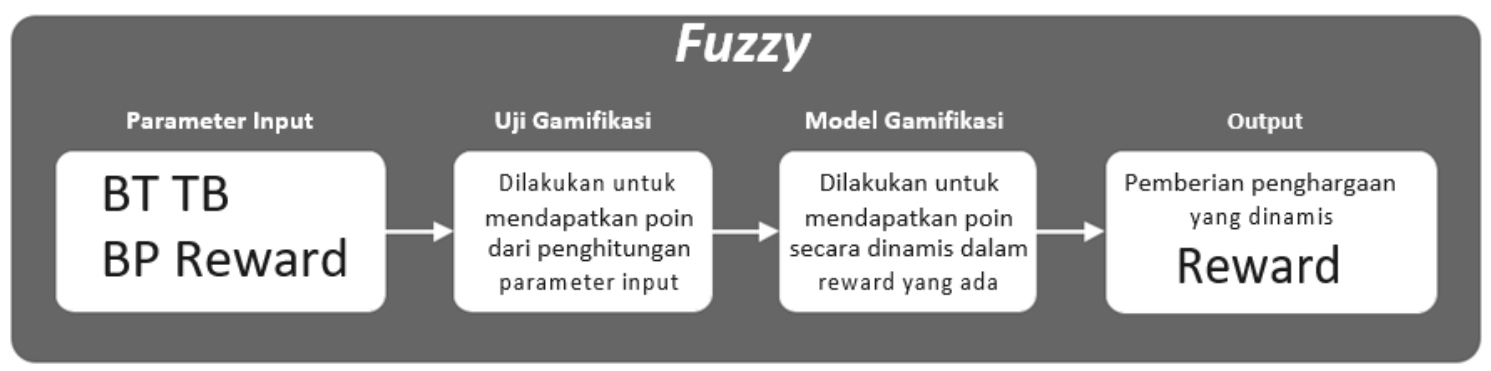

Gambar 6 Model umum sistem gamifikasi

\section{HASIL DAN PEMBAHASAN}

Berikut ini adalah proses yang terjadi pada sampel data dengan Banyak Transaksi (BT) adalah 6, Banyak Pesanan (BP) adalah 9 dan Total Belanja (TB) adalah Rp 18.000. Tahapan pertama yang diakukan adalah dengan mencari dari semua nilai derajat keanggotaan setiap kelas parameter input. Untuk parameter BT, akan dicari nilai detajat keanggotaannya dengan Fuzzy sesuai dengan Gambar 2, selanjutnya untuk parameter BP pencarian sesuai dengan Gambar 3 dan untuk parameter TB dengan menyesuaikan pada Gambar 4. Maka diperoleh nilai dengan derajat keanggotaan BT kecil : 0,67 dan sedang 0.33. Prosesnya dengan cara mamasukkan rumus yang terdapat pada gambar 3.2. Dengan menghitung (8-6)/(8-5), maka akan dihasilkan nilai 0,6666 yang dibulatkan menjadi 0,67. Sedangkan untuk BT Sedang dengan memasukkan rumus dan menghitung (6-5)/(8-5) maka akan menghasilkan nilai 0,3333 yang dibulatkan menjadi 0,33. Dengan demikian sudah diketahui nilai dari BT kecil dan BT sedang. Setelah mencari BT, maka mencari nilai dari BP (Banyak Pesanan). Dengan nilai BP 9, maka nilai ini termasuk dalam himpunan fuzzy Rata-rata dan Tinggi. Perhitungan dengan rumus (10-x) / (107), maka akan diperoleh nilai sebesar 0.33 . Untuk penghitungan tinggi, maka menggunakan rumus $(\mathrm{x}-7) /(10-7)$. Dengan memasukkan nilai yang BT maka memperoleh hasil 0,66. Untuk perhitungan TB masuk dalam bobot 1 untuk nilai Standard.

Setelah diketahui semua nilai dari tiap derajat keanggotaan pada semua parameternya, maka selanjutnya memasukkan semua nilai tersebut ke dalam aturan inferensi yang ditunjukkan oleh Tabel 1. Berdasarkan pada kasus diatas maka hasil rule yang didapat adalah aturan 4, aturan 6, aturan 14 dan aturan 16, ditunjukkan pada Tabel 2 sebagai berikut.

Tabel 2 Daftar aturan inferensi yang relevan

\begin{tabular}{|c|c|c|c|c|c|c|c|}
\hline Rule & \multicolumn{2}{|c|}{ BT } & \multicolumn{2}{c|}{ BP } & \multicolumn{2}{c|}{ TB } & Reward \\
\hline 4 & Kecil & 0.67 & Rata-rata & 0.33 & Standard & 1.00 & Bronze \\
\hline 6 & Kecil & 0.67 & Tinggi & 0.67 & Standard & 1.00 & Bronze \\
\hline 14 & Sedang & 0.33 & Rata-rata & 0.33 & Standard & 1.00 & Silver \\
\hline 16 & Sedang & 0.33 & Tinggi & 0.67 & Standard & 1.00 & Silver \\
\hline
\end{tabular}

Berdasarkan dari hasil rule-rule yang didapat dari proses memasukan nilai fungsi keanggotaan, maka didapatkan hasil reward BRONZE dan SILVER. Selanjutnya mencari nilai $\mathrm{n}$ dengan cara mencari nilai kelas yang terkecil. Dengan menampung pada variabel sebuah variabel yang digunakan untuk proses berikutnya. Proses selanjutnya adalah mencari nilai dari $\mathrm{Zn}$ atau titik potong dari $\mathrm{n}$ yang sudah dicari. Mencari nilai $\mathrm{Zn}$ bisa dengan menggunakan rumus yang ada dengan melihat ada diposisi mana titik potong yang ada. Dalam Gambar 5 sudah terdapat beberapa kondisi yang ada untuk menetukan pencarian Zn. Setelah semua proses 
menentukan nilai dari $\mathrm{n}$ dan $\mathrm{Zn}$ seperti ditunjukkan pada Tabel 3 sudah selesai semua, maka tahap terakhir adalah menentukan defuzzifikasinya.

Tabel 3 Daftar aturan inferensi yang relevan

\begin{tabular}{|c|c|c|c|c|c|c|c|c|c|c|}
\hline Rule & BT & & \multicolumn{2}{|c|}{ BP } & \multicolumn{2}{|c|}{ TB } & Reward & an & Zn & Z \\
\hline 4 & Kecil & 0.67 & Rata-rata & 0.33 & Standard & 1 & Bronze & 0.33 & 333.33 & 111.11 \\
\hline & & & & & & & & & & \\
\hline 6 & Kecil & 0.67 & Tinggi & 0.67 & Standard & 1 & Bronze & 0.67 & 266.67 & 197.78 \\
\hline & & & & & & & & & & \\
\hline 14 & Sedang & 0.33 & Rata-rata & 0.33 & Standard & 1 & Silver & 0.33 & 266.67 & 88.89 \\
\hline & & & & & & & & & & \\
\hline 16 & Sedang & 0.33 & Tinggi & 0.67 & Standard & 1 & Silver & 0.33 & 266.67 & 88.89 \\
\hline
\end{tabular}

Dengan mengalikan $n$ dan $Z n$ dan menjumlahkannya sesuai dengan persamaan (1) maka akan didapatkan hasil reward untuk pelanggan sebesar 280 poin. Pada Tabel 4 berikut adalah 30 data yang dimasukkan pada sistem gamifikasi.

Tabel 4 Pengujian data

\begin{tabular}{|c|c|c|c|c|c|}
\hline \multirow[t]{2}{*}{ No } & \multirow[t]{2}{*}{ BT } & \multirow[t]{2}{*}{$\mathbf{B P}$} & \multirow[t]{2}{*}{ TB } & \multicolumn{2}{|c|}{ Reward } \\
\hline & & & & Jenis Reward & Poin \\
\hline 1 & 3 & 3 & 12,000 & Bronze - Silver & 296 \\
\hline 2 & 5 & 4 & 16,000 & Bronze - Silver & 300 \\
\hline 3 & 2 & 3 & 12,000 & Bronze - Silver & 296 \\
\hline 4 & 5 & 6 & 24,000 & Bronze - Silver & 360 \\
\hline 5 & 7 & 7 & 28,000 & Silver - Gold & 933,33 \\
\hline 6 & 5 & 5 & 20,000 & Bronze - Silver & 200 \\
\hline 7 & 8 & 6 & 24,000 & Silver - Gold & 960 \\
\hline 8 & 4 & 5 & 25,000 & Silver - Gold & 800 \\
\hline 9 & 7 & 4 & 16,000 & Bronze - Silver & 313,33 \\
\hline 10 & 6 & 6 & 24,000 & Silver & 450,79 \\
\hline 11 & 3 & 4 & 16,000 & Bronze - Silver & 300 \\
\hline 12 & 4 & 5 & 21,000 & Bronze & 240 \\
\hline 13 & 5 & 6 & 24,000 & Bronze - Silver & 360 \\
\hline 14 & 6 & 3 & 12,000 & Bronze - Silver & 297,60 \\
\hline 15 & 3 & 6 & 24,000 & Bronze - Silver & 360 \\
\hline 16 & 4 & 7 & 28,000 & Silver - Gold & 800 \\
\hline 17 & 5 & 2 & 8,000 & Bronze & 200 \\
\hline 18 & 7 & 3 & 12,000 & Bronze - Silver & 301,33 \\
\hline 19 & 8 & 5 & 20,000 & Silver - Gold & 800 \\
\hline 20 & 6 & 10 & 40,000 & Silver - Gold & 866,67 \\
\hline 21 & 5 & 3 & 12,000 & Bronze - Silver & 296 \\
\hline 22 & 4 & 5 & 20,000 & Bronze & 200 \\
\hline 23 & 3 & 3 & 12,000 & Bronze - Silver & 296 \\
\hline 24 & 4 & 6 & 24,000 & Bronze - Silver & 360 \\
\hline 25 & 5 & 7 & 29,000 & Silver - Gold & 800 \\
\hline 26 & 5 & 7 & 28,000 & Silver - Gold & 800 \\
\hline
\end{tabular}




\begin{tabular}{|l|l|l|l|l|l|}
\hline 27 & 5 & 3 & 12,000 & Bronze - Silver & 296 \\
\hline 28 & 3 & 5 & 20,000 & Bronze & 200 \\
\hline 29 & 2 & 7 & 28,000 & Silver - Gold & 800 \\
\hline 30 & 7 & 8 & 32,000 & Silver - Gold & 920 \\
\hline
\end{tabular}

\section{KESIMPULAN DAN SARAN}

Kesimpulan yang dapat diambil dari penelitian ini adalah sistem dapat menentukan reward secara otomatis dengan menentukan parameter yang ada didalam transaksi penggangan. Terdapat 3 jenis reward yang diusulkan dalam penelitian ini : "BRONZE", "SILVER" dan "GOLD". Sistem gamifikasi menghasilkan perilaku dinamis reward untuk pelanggan $e$ commerce. Dalam aturan reward, penelitian ini memiliki 27 rule dan terdapat 3 parameter utama. Pada penelitian berikutnya dapat dilakukan penambahan rule yang akan menambahkan spesifikasi dari reward yang ada.

\section{DAFTAR PUSTAKA}

[1] Badan Pusat Statistik, "Jumlah Penduduk Miskin, Persentase Penduduk Miskin dan Garis Kemiskinan, 1970-2013," Badan Pusat Statistik, 2013. [Online]. Available: http://www.bps.go.id/tab_sub/view.php?kat=1\&tabel=1\&daftar=1\&id_subyek=23\&nota b=7. [Accessed: 10-Feb-2020].

[2] Badan Pusat Statistik, "Tabel Perkembangan UMKM pada Periode 1997 -2012," Badan Pusat Statistik, 2012. [Online]. Available: http://www.bps.go.id/tab_sub/view.php?kat=2\&tabel=1\&daftar=1\&id_subyek=13 $\&$ notab=45. [Accessed: 10-Feb-2020].

[3] Kementerian Koperasi dan Usaha Kecil dan Menengah, "Perkembangan Data Usaha Mikro, Kecil, Menengah (UMKM) dan Usaha Besar (UB) Tahun 2011-2012," Kementerian Koperasi dan Usaha Kecil dan Menengah, 2012. [Online]. Available: http://www.depkop.go.id/index.php?option=com_phocadownload\&view=category\&id=1 09:data-umkm-2012\&Itemid=93. [Accessed: 10-Feb-2020].

[4] G. Lucassen and S. Jansen, "Gamification in Consumer Marketing - Future or Fallacy?," Procedia - Soc. Behav. Sci., vol. 148, no. 2011, pp. 194-202, 2014.

[5] S. Deterding, K. O'Hara, M. Sicart, D. Dixon, and L. Nacke, "Gamification: Using game design elements in non-game contexts," Proc. 2011 Annu. Conf. Hum. Factors Comput. Syst. (CHI 2011), pp. 1-4, 2011.

[6] H. Park and J. Bae, "Analysis and survey of gamification," Adv. Sci. Technol. Lett., vol. 39, pp. 24-27, 2013.

[7] Bunchball, "Successful Gamification Case Studies and Examples," Bunchball, 2015. [Online]. Available: https://www.bunchball.com/customers/gamification-success-stories. [Accessed: 03-Feb-2020].

[8] I. I. Volkova, "Four pillars of gamification," Middle East J. Sci. Res., vol. 13, no. SPLISSUE, pp. 149-152, 2013.

[9] A. Knutas, M. Granato, and R. Van Roy, "Profile-Based Algorithm for Personalized Gamification in Computer-Supported Collaborative Learning Environments," 1st Work. Games-Human Interact., 2017.

[10] C. López and C. Tucker, "Towards Personalized Adaptive Gamification: A Machine Learning Model for Predicting Performance," IEEE Trans. Games, 2018.

[11] D. Rajanen and M. Rajanen, "Personalized Gamification: A Model for Play Data Profiling," in Proceedings of the Data-Driven Gamification Design Workshop, 2017. 
[12] É. Lavoué, B. Monterrat, M. Desmarais, and S. George, "Adaptive Gamification for Learning Environments," IEEE Trans. Learn. Technol., p. 1, 2018.

[13] B. Barna and S. Fodor, "A Data-Driven Approach to Analyze User Behavior on a Personalized Gamification Platform," in International Conference on Games and Learning Alliance, 2019, pp. 266-275.

[14] S. I. Pangestu, H. Haryanto, and E. Dolphina, "Item Adaptif Menggunakan Logika Fuzzy Mamdani Pada Game Bertema Adaptive Item Using Mamdani Fuzzy Logic in River Sanitation," CCIT, vol. 11, no. 1, pp. 58-68, 2018.

[15] A. N. Putri, L. Hermawan, M. Hariadi, and A. Graf, "Game Scoring Non Player Character Menggunakan Agen Cerdas Berbasis Fuzzy Mamdani," in Seminar Nasional Teknologi Informasi \& Komunikasi Terapan 2014, 2014, vol. 2014, no. November, pp. 142-149.

[16] M. A. Darmawan, H. Haryanto, and Y. Rahayu, "Perilaku Penyerangan NPC Berbasis Fuzzy Sugeno pada Game Action-RPG Bertema Sejarah Geger Pacinan," Creat. Inf. Technol. J., vol. 4, no. 3, pp. 195-206, 2017. 